\title{
Kajian Beberapa Cara Fermentasi yang Dilakukan oleh Petani terhadap Mutu Biji Kakao (Theobroma cacao L.)
}

\author{
NI LUH MADE PRADNYAWATHI*), I KETUT ARSA WIJAYA, \\ I NYOMAN SUTEDJA, DAN ANAK AGUNG MADE ASTININGSIH \\ Program Studi Agroekoteknologi, Fakultas Pertanian, Universitas Udayana \\ ${ }^{*}$ E-mail: npradnyawathi@yahoo.com
}

\begin{abstract}
Study of Assorted Fermentation Methods Conducted by Local Farmers on the Quality of VCocoa Beans (Theobroma Cacao L.). Various fermentation methods have been done by local farmers, however there has been no report on the quality of cocoa beans from those methods. This study aims were to identify various ways of cocoa beans fermentation conducted by local farmers; to compare between quality of fermented beans produced by local farmers and suggested quality of fermented beans; and o obtain a simple fermentation method which resulted in good quality beans and suitable practice for local farmers. The research wasconducted in Tabanan Regency, Province of Bali through field survey with observation and interview method, and supported with literature study. According to field observation and analysis of fermented cocoa beans taken from the local farmers, it can be concluded that most of local farmers did not fermented their kakao seeds. Thus, the fermentation done by utilizing a plastic sack, a bamboo basket or a wooden box lined and covered with banana leaves. The research also found that implementing similar fermentation methods to the seed did not always resulting similar quality of cocoa beans. Finally, the simplest method for local farmers to ferment the cocoa seed was the fermentation by utilizing basket lined and covered with banana leaves with at least $90 \mathrm{~kg}$ wet beans.
\end{abstract}

Keywords: Cocoa, Fermentation, Plastick sack, Bamboo basket, Wooden box

\section{PENDAHULUAN}

Kakao Indonesia tidak kalah dengan kakao dunia. Apabila dilakukan fermentasi dengan baik cita rasa kakao Indonesia akan setara dengan kakao yang berasal dari Ghana. Di samping itu kelebihan dari kakao Indonesia adalah tidak mudah meleleh sehingga kakao Indonesia cocok dipakai untuk blending (Baon et al., 2005).

Fermentasi merupakan proses yang paling penting pada tahapan pasca panen biji kakao. Proses ini tidak hanya bertujuan untuk melepaskan biji kakao dari pulp dan mematikan biji, namun terutama juga untuk memperbaiki dan membentuk citarasa kakao yang enak dan menyenangkan serta mengurangi rasa pahit dan sepat pada biji (Wood, 1975). Bila biji tidak difermentasi, biji akan terasa pahit, sepat dan tidak ada aroma khas kakao ketika diolah (Schwan \& Wheals, 2004). 


\section{NI LUH MADE PRADNYAWATHI. et al. Kajian Beberapa Cara Fermentasi yang Dilakukan...}

Fermentasi menyediakan kondisi yang sesuai untuk berlangsungnya reaksi kimia dan biokimia di dalam keping biji. Reaksi kimia dan biokimia di dalam keping biji ini mendorong terbentuknya prekursor cita rasa dan warna kakao (Wood, 1975). Dengan adanya gula dan keasaman yang tinggi $(\mathrm{pH}$ 3-5) dari pulp maka akan merupakan kondisi yang baik untuk perkembangan mikroorganisme. Tahap pertama ragi mengubah gula menjadi alkohol kemudian selanjutnya oleh bakteri asam asetat alkohol dirubah menjadi asam asetat. Masuknya asam asetat ke dalam biji akan mematikan biji dan mengaktifkan enzim-enzim di dalam biji sehingga akan terjadi perubahan kimiawi yang akan memperbaiki rasa warna dan aroma kakao (Afoakwa et al., 2014, Apriyanto et al., 2016).

Fermentasi biji yang baik umumnya memerlukan tonase biji yang tinggi untuk memperoleh suhu yang sesuai di samping itu membutuhkan waktu yang lama. Hal ini menyebabkan petani tidak melakukan fermentasi karena ingin mendapatkan uang lebih cepat. Namun demikian kadang-kadang ada juga petani yang melakukan fermentasi seadanya untuk menghilangkan pulp dari biji tetapi belum ada penelitian yang mempelajari tentang mutu hasil biji dari cara-cara fermentasi yang dilakukan oleh petani tersebut.

Penelitian ini bertujuan untuk mengidentifikasi cara-cara fermentasi biji kakao yang dilakukan oleh petani, membandingkan mutu hasil biji fermentasi yang dilakukan oleh petani dengan mutu hasil biji fermentasi anjuran serta mendapatkan cara fermentasi yang sederhana dengan mutu hasil biji yang baik.

\section{METODE PENELITIAN}

Penelitian dilakukan di Kabupaten Tabanan. Bahan yang digunakan adalah biji hasil fermentasi petani. Metode yang digunakan adalah survey lapang dengan observasi dan wawancara. Sumber data ada dua yaitu data sekunder dan data primer. Data sekunder diperoleh dari Dinas Kehutanan dan Perkebunan Kabupaten Tabanan dan pengguna produk kakao. Data primer diperoleh dari observasi dan wawancara langsung ke lapangan dan analisis biji hasil fermentasi yang diperoleh di lapangan.

Pelaksanaan penelitian terdiri dari empat tahap kegiatan, yaitu (1) pengumpulan data sekunder, (2) survey lapangan di wilayah Kabupaten Tabanan berdasarkan data sekunder (3) Analisis laboratorium hasil fermentasi yang diperoleh di lapangan (4) Membandingkan hasil analisis biji kakao dengan mutu biji fermentasi yang dianjurkan.

Variabel yang diamati adalah: lama fermentasi, mutu fisik biji kakao kering, meliputi : jumlah biji kering per 100 gram, kelompok mutu biji, kadar nib (biji yang sudah dibersihkan dari kulit arinya), kadar kulit ari, uji belah/cut test (metode Senanayake et al., 1996 dalam kustyawati \& setyani, 2008), serta mutu kimia biji kakao kering, meliputi : kadar lemak, kadar air dan pH. Semua analisis dilakukan di Laboratorium Analisis Hasil Pertanian, Fakultas Teknologi Pertanian, Universitas Udayana.

\section{HASIL DAN PEMBAHASAN}

Dari data yang diperoleh di Dinas Kehutanan dan Perkebunan Kabupaten 
Tabanan luas areal perkebunan kakao di Kabupaten Tabanan adalah 4.532,31 ha., dan dari luasan itu 3.355,74 ha merupakan tanaman yang menghasilkan (TM), sisanya 913,99 ha. tanaman belum menghasilkan (TBM) dan 283,24 ha. tanaman yang rusak (TTM/TR) dengan produksi kakao total $2.067,18$ ton dan produktivitas $620 \mathrm{~kg} / \mathrm{ha} / \mathrm{th}$. Untuk sebarannya, hampir di setiap kecamatan di Kabupaten Tabanan ada tanaman kakao, namun yang paling banyak adalah di Kecamatan Selemadeg Barat.

Umumnya petani yang ditemui tidak melakukan fermentasi pada biji kakaonya karena beberapa alasan, 1) buah yang didapat sedikit, 2) petani ingin mendapatkan uang lebih cepat, dan 3) harga yang diperoleh dari pengepul untuk kakao yang difermentasi tidak berbeda jauh dengan biji yang tidak difermentasi (hasil wawancara dengan Dinas Kehutanan dan perkebunan Kabupaten Tabanan serta ketua kelompok tani di Banjar Manunggul, Desa Bajra Utara, Kecamatan Selemadeg, Kabupaten Tabanan, 2017 ).

Dari pengamatan langsung ke lapangan dengan melihat data sebaran tanaman kakao di lapangan, kondisi tanaman kakao petani umumnya tidak mendapat pemeliharaan yang baik. Tanaman kurang terpelihara dan buahbuah yang ada kebanyakan busuk berwarna hitam, kemungkinan karena serangan hama penggerek buah kakao (PBK) dan penyakit busuk buah. Namun ada juga beberapa petani yang melakukan fermentasi seadanya dengan cara menyimpan biji basah dalam kampil selama 3-4 hari kemudian langsung dijemur. Cara ini banyak dilakukan oleh petani di Desa Rijasa, Kecamatan Penebel, Kabupaten Tabanan dan di Desa Tunjuk, Kecamatan Tabanan, Kabupaten Tabanan.
Data yang diperoleh dari sebuah perusahan pengolahan biji kakao yang berada di Desa Cau, Kecamatan Marga, Kabupaten Tabanan, ada beberapa petani dan kelompok tani yang melakukan fermentasi karena perusahan tersebut memberi persyaratan tertentu untuk biji yang bisa diterima dan diberi harga yang memadai. Petani-petani dan kelompok tani ini melakukan fermentasi dengan menggunakan keranjang bambu dan kotak kayu.

Cara fermentasi dengan keranjang bambu di Br. Umabali, Desa Geluntung, Kecamatan Marga, Kabupaten Tabanan (Keranjang bambu 1), ukuran keranjang bambu diameter $70 \mathrm{~cm}$ tinggi $60 \mathrm{~cm}$, berat biji basah $80 \mathrm{~kg}$, dialasi daun pisang di bagian bawah dan juga di samping kemudian ditutup daun pisang dan plastik tebal paling atas. Pembalikan dilakukan pada hari kedua, hari ketiga dan hari keempat fermentasi sudah selesai, biji kemudian dicuci dan selanjutnya dijemur.

Cara fermentasi keranjang bambu kedua adalah di Desa Cau, Kecamatan Marga (Keranjang bambu 2) dan cara fermentasi dengan keranjang bambu ketiga di Dusun Basangbe, Desa Perean Kangin, Kecamatan Baturiti, Kabupaten Tabanan (keranjang bambu 3) dengan ukuran keranjang bambu diameter $70 \mathrm{~cm}$, tinggi $20 \mathrm{~cm}$, dengan berat biji basah 30-50 kg Biji. Biji dialasi dan ditutup daun pisang, paling atas ditutup dengan kampil. Pembalikan dilakukan hari kedua, ketiga dan hari keempat kemudian dicuci dan selanjutnya dijemur.

Cara Fermentasi dengan kotak kayu dilakukan oleh seorang petani di Br. Pesagi, Desa Jegu, Kecamatan Penebel, Kabupaten Tabanan (Kotak 1). Kotak kayu disekat 


\section{NI LUH MADE PRADNYAWATHI. et al. Kajian Beberapa Cara Fermentasi yang Dilakukan...}

dengan ukuran $40 \mathrm{~cm} x 40 \mathrm{~cm} x 60 \mathrm{~cm}$ dengan berat biji basah $40 \mathrm{~kg}$. Biji dialasi dan ditutup dengan daun pisang. Pembalikan dilakukan pada hari ketiga dan hari keempat langsung dicuci dan dijemur. Kotak kayu disekat karena kuantitas biji basah kecil. Kotak kayu kedua di Kelompok Tani Wija Amerta Desa Angkah, Kecamatan Selemadeg Barat Kabupaten Tabanan (Kotak kayu 2). Kotak kayu berukuran $50 \mathrm{~cm} \times 60 \mathrm{~cm} \times 50 \mathrm{~cm}$, bisa menampung sampai $100 \mathrm{~kg}$ biji basah, namun bila jumlah biji sedikit maka kotak kayu tersebut bisa disekat-sekat. Biji dialasi daun pisang di bagian bawah dan samping dan selanjutnya ditutup lagi dengan daun pisang dan paling atas ditutup plastik. Pembalikan dilakukan pada hari ketiga, hari keempat dan hari kelima langsung dicuci dan dijemur.

Di Kelompok Tani Wija Amerta juga mempunyai kotak fermentasi besar ukuran 200x100x100 $\mathrm{cm}$ yang memuat 1 ton biji (Gambar 10). Kotak ini digunakan bila anggota kelompok mempunyai kuantitas biji yang besar.

Biji kering hasil fermentasi diambil dari masing-masing petani yang melakukan cara fermentasi di atas, kemudian biji-biji tersebut dianalisis untuk mutu fisik dan mutu kimianya di Laboratorium Analisis Hasil Pertanian, Fakultas Teknologi Pertanian, Universitas Udayana. Hasil analisis biji kakao fermentasi dapat dilihat pada Tabel 1.

Tabel 1. Hasil analisis biji kakao fermentasi yang didapat dari petani

\begin{tabular}{|c|c|c|c|c|c|c|c|c|c|c|}
\hline $\begin{array}{l}\text { Cara } \\
\text { Fermentasi }\end{array}$ & $\begin{array}{l}\text { Jumlah } \\
\text { biji/100g } \\
\text { (kelas) }\end{array}$ & $\begin{array}{l}\text { Kadar } \\
\text { kulit } \\
\text { ari } \\
(\%)\end{array}$ & $\begin{array}{l}\text { Kadar } \\
\text { NIB } \\
(\%)\end{array}$ & $\begin{array}{l}\text { Nilai } \\
\text { Cut } \\
\text { Test }\end{array}$ & $\begin{array}{l}\text { Suhu } \\
\text { ideal } \\
\left({ }^{\circ} \mathrm{C}\right)\end{array}$ & $\mathrm{pH}$ & $\begin{array}{l}\text { Kadar } \\
\text { Lemak } \\
(\%)\end{array}$ & $\begin{array}{l}\text { Kadar } \\
\text { Air } \\
(\%)\end{array}$ & $\begin{array}{l}\text { Variabel } \\
\text { sesuai } \\
\text { anjuran }\end{array}$ & $\begin{array}{l}\text { Persentase } \\
(\%) \text { sesuai } \\
\text { anjuran }\end{array}$ \\
\hline ANJURAN & & $12-13$ & $>87$ & $>3$ & $45-48$ & $\begin{array}{c}5,2- \\
5,8\end{array}$ & $50-51$ & 6-7 & & \\
\hline Kampil & $123(\mathrm{~S})$ & 15,75 & 84,25 & 0,92 & 36 & 6,39 & 54,19 & 7,03 & $0 / 7$ & 0 \\
\hline $\begin{array}{l}\text { Keranjang } \\
\text { bambu } 1\end{array}$ & $88(\mathrm{~A})$ & 08,00 & $92,00 *$ & $3,20 *$ & 42 & 5,03 & 54,11 & $6,11 *$ & $3 / 7$ & 43 \\
\hline $\begin{array}{l}\text { Keranjang } \\
\text { bambu } 2\end{array}$ & $81(\mathrm{AA})$ & 08,70 & $91,30^{*}$ & 2,76 & 40 & 6,42 & 47,94 & $6,82 *$ & $2 / 7$ & 29 \\
\hline $\begin{array}{l}\text { Keranjang } \\
\text { bambu } 3\end{array}$ & $104(\mathrm{~B})$ & 09,73 & $90,27 *$ & 2,44 & 39 & 5,94 & 42,49 & 7,89 & $1 / 7$ & 14 \\
\hline $\begin{array}{l}\text { Kotak kayu } \\
1\end{array}$ & $100(\mathrm{~A})$ & 10,29 & $89,71 *$ & 1,64 & 40 & 6,42 & 44,17 & 7,86 & $1 / 7$ & 14 \\
\hline $\begin{array}{l}\text { Kotak kayu } \\
2\end{array}$ & $115(\mathrm{C})$ & 17,15 & 82,85 & $3,12 *$ & $47 *$ & $5,58^{*}$ & 41,27 & $6,54 *$ & $4 / 7$ & 57 \\
\hline Kotak besar & $103(\mathrm{~B})$ & 15,68 & 84,32 & $3,28^{*}$ & - & $5,45^{*}$ & 46,72 & $6,54 *$ & $3 / 7$ & 50 \\
\hline
\end{tabular}


Variabel-variabel yang berkaitan langsung dengan cara fermentasi adalah nilai uji belah dan suhu maksimum biji saat fermentasi. Variabel-variabel lain selain dipengaruhi oleh cara fermentasi juga dipengaruhi oleh jenis kakao dan faktor lain dalam penangan pasca panen biji kakao seperti pencucian setelah fermentasi, penjemuran dan penyimpanan. Menurut Ganda Putra \& Wartini (1998 dalam Ganda Putra et al., 2007). Mutu biji kakao kering sangat dipengaruhi oleh beberapa faktor pra panen, seperti sifat genetis tanaman, lingkungan fisik, dan praktek budidaya, serta penanganan pasca panen seperti pemanenan, fermentasi, pencucian, pengeringan, dan pengangkutan. Sifat genetis tanaman tidak hanya menentukan citarasa, tetapi juga kadar lemak, kadar kulit, dan berat biji.

Jumlah biji per 100 gram menentukan kelas biji. Jumlah biji per 100 gram berbedabeda tergantung dari jenis kakaonya dan ada atau tidaknya sisa pulp yang masih menempel. Dari hasil observasi di lapangan, kelas biji dari masing-masing cara fermentasi berbeda-beda karena biji diambil dari tempat yang berbeda sehingga kemungkinan jenis kakaonya berbeda di samping juga factor lingkungan dan cara pemeliharaan yang berbeda. Hasil penelitian Elisabeth \& Setijorini (2009) perlakuan tingkat fermentasi tidak berpengaruh nyata pada jumlah biji kering per 100 gram tetapi berpengaruh terhadap kadar kulit ari biji kakao karena selama proses fermentasi terjadi penguraian pulp. Sisa pulp ditentukan oleh fermentasi dan pencucian setelah fermentasi dan kadar kulit ari yang tinggi berpengaruh pada rendahnya kadar nib biji kakao. Menurut Mulato et al. (2004) kadar kulit ari yang memenuhi spesifikasi mutu biji kakao untuk bahan baku produk cokelat adalah $12-13 \%$; dan kadar nib tidak kurang dari 87-88\%. Pada perlakuan keranjang bambu, kadar kulit ari sangat rendah, di bawah kadar kulit ari yang dianjurkan (Tabel 1). Keranjang bambu 1, masuk katagori kelas A (88 biji/100g), Keranjang bambu 2, kelas AA (81 biji/100 g) dan keranjang bambu 3 kelas B (104 biji/100g) dengan kadar kulit ari berturut-turut 8,0\%, 8,70\%, dan $9,73 \%$. Kadar kulit ari yang rendah akan menyebabkan kulit biji rapuh saat ditumpuk sementara kadar kulit yang tinggi cenderung lebih kuat sehingga biji dapat disimpan lebih lama. Namun pada fermentasi dengan kampil, kotak kayu 2 dan kotak besar kadar kulit ari melebihi anjuran. Tebalnya sisa pulp pada fermentasi dengan kampil disebabkan oleh kurangnya fermentasi dan tidak dilakukannya pencucian setelah fermentasi, sementara pada kotak kayu diduga pencucian setelah fermentasi kurang.

Faktor utama yang juga menentukan kualitas biji kakao fermentasi adalah derajat fermentasi dan keasaman $(\mathrm{pH})$ biji. Derajat fermentasi diukur dengan nilai uji belah (cut test). Uji belah dipakai untuk mengetahui apakah biji sudah terfermentasi dengan sempurna ataukah tidak. Menurut Senanayake et al.,(1996 dalam kustyawati \& setyani, 2008) nilai uji belah yang baik adalah di atas 3 di mana biji berwarna coklat keunguan dengan warna coklat yang lebih dominan. Dari beberapa cara fermentasi yang dilakukan, nilai uji belah yang memenuhi adalah fermentasi dengan keranjang bambu 1 $(3,20)$, fermentasi dengan kotak kayu 2 $(3,12)$ dan fermentasi dengan kotak besar $(3,28)$. Bila dikaitkan dengan suhu 


\section{NI LUH MADE PRADNYAWATHI. et al. Kajian Beberapa Cara Fermentasi yang Dilakukan...}

fermentasi, nilai uji belah yang melebihi nilai 3 didapat pada fermentasi dengan suhu maksimum yang melebihi $40^{\circ} \mathrm{C}$ (keranjang bambu 1: $42{ }^{\circ} \mathrm{C}$, kotak kayu 2: $47{ }^{\circ} \mathrm{C}$, sementara suhu pada kotak kayu besar tidak teramati karena waktu observasi di lapangan fermentasi sudah lewat beberapa bulan sebelumnya). Didapatnya suhu yang sesuai untuk terjadinya fermentasi yang sempurna berkaitan dengan berat biji basah pada saat fermentasi. Berat biji basah pada keranjang bambu 1 lebih kurang $80 \mathrm{~kg}$, pada kotak kayu 2 adalah $100 \mathrm{~kg}$ dan kotak kayu besar 1 ton. Fermentasi dengan kampil, keranjang bambu 2, keranjang bambu 3 dan kotak kayu 1 menunjukkan nilai belah di bawah 3 yang berarti warna ungu dominan terhadap warna coklat. Hal ini menunjukkan fermentasi yang terjadi kurang sempurna. Keadaan ini diduga berkaitan dengan berat biji yang tidak memenuhi syarat untuk mencapai suhu yang optimal untuk terjadinya fermentasi yang sempurna. Wood (1975) menyatakan berat biji basah yang dibutuhkan untuk fermentasi sempurna tidak kurang dari $90 \mathrm{~kg}$. Berat biji basah pada cara-cara fermentasi ini di bawah $50 \mathrm{~kg}$ dan suhu maksimum yang dicapai di bawah $40{ }^{\circ} \mathrm{C}$.

Dilihat dari pH, Wood \& Lass (2001), menyatakan perusahan pengolah kakao menghendaki biji dengan $\mathrm{pH}$ antara 5,2 - 5,8 untuk bisa menghasilkan cocoa butter yang berkualitas. Cara fermentasi keranjang bambu 1, kotak kayu 1 dan kotak besar menghasilkan $\mathrm{pH}$ yang sesuai dengan yang dipersyaratkan yaitu $5,2-5,8$. Menurut Dumadi (2000), pH biji kakao harus di atas 5,0 agar bisa menghasilkan citarasa kakao yang khas. Biji kakao dengan $\mathrm{pH}$ relatif rendah akan menghilangkan pembentukan calon aroma, namun $\mathrm{pH}$ biji yang terlalu tinggi (lebih dari 6,0) akan menyebabkan kerusakan aroma yang disebabkan oleh tumbuhnya mikroorganisme yang dapat mendegradasi atau merusak asam amino.

Dilihat dari kadar lemak, cara fermentasi kampil dan keranjang bambu 1 kadar lemak berturut-turut 54,19 dan 54,11 melebihi dari pada anjuran (50-51\%), sementara cara fermentasi yang lain jauh di bawah kadar lemak anjuran. Kadar lemak ini juga melebihi kadar lemak kakao indonesia pada umumnya yaitu 49-52\%. Kadar lemak kakao Afrika Barat mencapai 56-58 \% (Wood, 1975). Langkong et al. (?) menyebutkan bahwa lemak adalah komponen yang paling mahal dari biji kakao sehingga kadar lemak dipakai sebagai salah satu tolok ukur penentuan harga. Kandungan lemak dipengaruhi oleh perlakuan jenis bahan tanaman, faktor musim, perlakuan pasca panen seperti tingkat fermentasi, kadar air biji dan kadar kulit.

Kadar air biji yang dianjurkan adalah 6-7 \%. Cara fermentasi yang memenuhi anjuran ini adalah keranjang bambu 1, keranjang bambu 2, kotak kayu 2 dan kotak besar. Winarno (1997) menyatakan kestabilan optimum bahan pangan tercapai pada kadar air 3- 7\%. Pada Kisaran ini bahan pangan tidak mudah terserang oleh mikroorganisme dan bahan pangan tahan terhadap reaksi-reaksi kimia yang merusak seperti oksidasi lemak. Kadar air biji kakao kering di bawah 5\% dapat mengakibatkan kulit biji akan mudah pecah atau rapuh (Wahyudi et al., 1998).

Secara keseluruhan, cara fermentasi yang memberikan persentase sesuai anjuran yang paling tinggi berturut-turut adalah 
fermentasi dengan kotak kayu 2 (57\%) dengan memenuhi kriteria untuk variable nilai uji belah, suhu ideal, $\mathrm{pH}$ dan kadar air; fermentasi dengan kotak kayu besar (50\%) dengan memenuhi kriteria untuk variabel nilai uji belah, $\mathrm{pH}$, dan kadar air; dan fermentasi dengan keranjang bambu 1 (43\%) dengan memenuhi kriteria untuk variable kadar nib, nilai uji belah, dan kadar air. Sedangkan fermentasi dengan kampil tidak memenuhi persyaratan mutu biji (Tabel 1). Walaupun memberikan mutu hasil biji yang bagus, fermentasi dengan kotak besar sulit ditiru oleh petani karena membutuhkan tonase biji yang tinggi.

\section{SIMPULAN}

Dari hasil observasi dan wawancara di lapangan serta dari hasil analisis biji kakao fermentasi yang diambil dari petani dapat disimpulkan kebanyakan petani tidak memfermentasi biji kakaonya. Cara-cara fermentasi yang dilakukan oleh petani adalah dengan kampil, keranjang bambu, dan kotak kayu yang dialasi dan ditutup dengan daun pisang dan di atasnya ditutup plastik atau karung goni. Cara-cara fermentasi yang sama belum tentu memberikan hasil yang sama karena di samping cara fermentasi, banyak hal lain yang berpengaruh terhadap mutu biji kakao kering. Cara fermentasi yang paling sederhana yang bisa dilakukan oleh petani adalah dengan menggunakan keranjang bambu yang dialasi dengan daun pisang dan ditutup dengan daun pisang dan plastik di bagian atasnya dengan berat biji basah tidak kurang dari $90 \mathrm{~kg}$.

\section{DAFTAR PUSTAKA}

Baon, J.B.; Herman dan Purwoto, A. 2005. Prospek Dan Arah Pengembangan Agribisnis Kakao Di Indonesia. Badan Penelitian Dan Pengembangan Pertanian Departemen Pertanian

Dumadi, S. R. 2000. Hubungan penyimpanan buah kakao dengan perubahan gula dan pengasaman biji selama proses fermentasi. Jurnal Sains dan Teknologi Indonesia, 2 (3); 33-39

Elisabeth, D. A.A dan L.E. Setijorini. 2009. Keragaan Mutu Biji Kakao Kering dan Produk Setengah Jadi Cokelat pada Berbagai Tingkatan Fermentasi. Jurnal Matematika, Sains, dan Teknologi Vol. 9 (1): 36-46

Ganda Putra, G.P., Harijono, Tri Susanto, Sri Kumalaningsih, dan Aulanni'am. 2007. Ekstraksi dan Karakterisasi Enzim Poligalakturonase Endojinus Pada Pulp Biji Kakao. Jurnal Teknologi Pertanian, Vol. 8 (1): 1 - 9

Kustyawati, M.E. dan Setyani, S. 2008. Pengaruh Penambahan Inokulum Campuran terhadap Perubahan Kimia dan Mikrobiologi selama Fermentasi Coklat. Jurnal Teknologi Industri dan Hasil Pertanian, Vol 13 (2) : 73 - 84

Langkong J., E. Ishak, M. Bilang dan J. Muhidong. ? . Pemetaan Lemak Dari Biji Kakao (Theobroma cocoa L) di Sulawesi Selatan. pasca.unhas.ac.id/jurnal/files/1c968d54 ed2d033c105227669ae4b8b3. Diakses tgl 25 Nopember 2017.

Wahyudi, T., Yusianto dan Sulistyowati, 1988. Masalah Keasaman Biji Kakao dan Beberapa Cara Untuk Mengatasinya. Prosiding Komunikasi Teknis Kakao Balai Penelitian Perkebunan, Jeber.

Winarno, F. G. 1997. Kimia pangan dan gizi. Jakarta: PT. Gramedia Pustaka Utama.

Wood, G.A.R. 1975. Cocoa. $3^{\text {rd }}$. ed. Longman, London and New York 
NI LUH MADE PRADNYAWATHI. et al. Kajian Beberapa Cara Fermentasi yang Dilakukan...

Wood, G.A.R., dan R.A. Lass. 2001. Cocoa. 4th ed. Longman. London

Mulato, S., S. Widyotmo dan Handaka. 2002 Disain Teknologi Pengolahan Pasta, Lemak dan Bubuk Coklat untuk Kelompok Tani. Warta Penelitian dan Pengembangan Pertanian, Badan Litbang Pertanian, Departemen Pertanian. Diakses melalui http://pustaka.bogor.net.

Afoakwa, E.O., Budu, A.S., Mensah-brown, H., dan Felix, J. (2014). Changes in biochemical and physico-chemical qualities during drying of pulp preconditioned and fermented cocoa (Theobroma cacao) beans. Journal of Nutritional Health and Food Science 2: 1-8.

Apriyanto, M., Sutardi, Supriyanto dan Harmayani, E. (2016). Study on Effect of Fermentation to quality parameter of cocoa bean Indonesia. Asian Journal Diary and Food Reseacrh 35(2): 160163.

Schwan, R.F. dan Wheals, A.E. (2004). The microbiology of cocoa fermentation and its role in chocolate quality. Critical Reviews in Food Science and Nutrition 44: 205-221. 